\title{
A NOÇÃO DE EQUIVALÊNCIA QUANDO SE TRADUZ MARCAS GRAMATICAIS: O CASO DE MAS E SUAS TRADUÇÕES PARA O FRANCÊS E O INGLÊS
}

\begin{abstract}
RESUMO: Este estudo, baseado em corpora paralelos, concentra-se nas relações entre os marcadores MAS (em português), MAIS (em francês) e BUT (em inglês) (Aubert, 1998) e no conceito de equivalência. Tendo em vista a história da tradução, muito tem sido dito sobre essa noção, que, direta ou indiretamente, tem sido usada de diferentes formas pelos estudiosos da área. Este artigo chama a atenção para a subjacente noção matemática de equivalência normalmente presente na lexicografia bilingue tradicional, que, em geral, exclui a definição e a contextualização dos verbetes, em especial em dicionários português-francês e português-inglês. Os resultados da pesquisa mostraram que as unidades gramaticais observadas apresentam particularidades que variam de acordo com seu contexto de uso, o que dá origem a um número variado de correspondentes e especificidades tradutórias, diferentemente do que é oferecido em dicionários bilingues para MAS.
\end{abstract}

Marion Celli*

PALAVRAS-CHAVE: Estudos da tradução; Equivalência; Lexicografia bilingue; Linguística de corpus; MAS.

* Mestranda do Programa de Estudos Linguísticos, Literários e Tradutológicos em Francês da FFLCH - USP.

TRADTERm, 16, 2010, p. 313-341 
ABSTRACT: This study, based on a parallel corpora, focuses on the non-equivalent relationships between the markers MAS (in Portuguese), MAIS (in French) and BUT (in English) (Aubert, 1998).Taking into account the history of translation studies, much has been said about the notion of equivalence. Directly or indirectly, translators and researchers have been using the concept in several different ways. Given the lack of definition and contextualization in bilingual dictionaries (Portuguese-French and Portuguese-English), this article calls attention to the underlying mathematical notion of equivalence in traditional bilingual lexicography. Each and every grammatical item, however, presents specific patterns which vary according to its context of use. The results showed a relevant number of correspondents and translating specificities when compared to what is offered by bilingual dictionaries for MAS.

KEYWORDS: Translation studies; Equivalence; Bilingual lexicography; Corpus linguistics; MAS.

\section{Introdução}

Em Translation theory before the twentieth century, Munday (2005) retoma, como um de seus objetivos principais, o velho debate entre tradução palavra por palavra (word-for-word) e tradução sentido por sentido (sense-for-sense) no período anterior ao século XX. Para isso, trata especialmente das considerações de Cícero, São Jerônimo, Dolet, Lutero, Dryden, Tytler e Schleiermacher, que muito contribuíram para os Estudos da Tradução. Ao longo de seu texto, é possível observar como, desde o séc. I a.C. de Cícero, a discussão sobre fidelidade ao texto original - seja ela relacionada à forma ou ao conteúdo - é muito recorrente. Embora tal discussão ainda seja relevante para os estudos tradutológicos, nota-se, após os anos 40, uma preocupação com o conceito de equivalência. Apesar de alguns autores utilizarem a palavra equivalente como produto da tradução, sem se preocupar com as implicações do termo, são muitas as discussões teóricas que envolvem sua definição.

TradTerm, 16, 2010, p. 313-341 
A emergência do termo de equivalência na Ciência da Tradução é normalmente associada à visão matemática do termo, em que simetria e reflexividade definem-se como suas características principais. Assim, ao transpor a mesma palavra para a tradução, transpõe-se, ao mesmo tempo, a noção de igualdade. Nota-se, assim, a complexidade da questão, uma vez que tal debate não se resume apenas a uma discussão teórica; antes envolve implicações práticas que a fórmula original = tradução gera para a prática da tradução.

Quando se quer traduzir marcas gramaticais, por exemplo, normalmente se faz uso de dicionários bilíngues, pelos quais se buscam opções de correspondente(s) na língua-alvo. A partir de uma consulta a dicionários bilíngues português-francês e português-inglês, notou-se, no entanto, que à marca gramatical adversativa do português brasileiro (PB) MAS são apresentadas poucas possibilidades tradutórias em relação ao leque de variação tradutológica que a unidade pode assumir em francês e em inglês. Assim, muitas entradas analisadas ofereciam, respectivamente, as opções MAIS e BUT como seus equivalentes - i.e. MAS = MAIS e MAS = BUT - , uma vez que, além de na maioria das vezes não haver outras possibilidades de tradução, os verbetes eram descontextualizados.

Através de um estudo baseado em corpora paralelos (Olohan, 2004; Halliday, Teubert, Yallop \& Germáková, 2004), pôde-se observar, por outro lado, que MAS possui uma significativa variação tradutória em francês e em inglês, além de apresentar alterações no posicionamento das traduções em relação à língua-fonte, o PB. É importante, dessa forma, ressaltar a necessidade de definição e contextualização em verbetes bilíngues (Zavaglia, 2008), já que os modelos tradicionais não levam em conta aspectos sintático-pragmáticos como os levantados neste trabalho. Tendo em vista tal problemática, pretendemos discutir as consequências da noção de equivalência para a elaboração de verbetes de dicionários bilíngues, uma vez que não vemos a tradução como igualdade, mas como diferença (Rodrigues, 2000). Assim, após uma breve revisão sobre o conceito, exemplificaremos sua aplicabilidade nas obras lexicográficas consultadas para, em seguida, discutir, através das modalida- 
des tradutórias de Aubert (1998), as relações entre MAS e suas traduções para o francês e o inglês a partir de um corpus paralelo literário. Vale notar, ainda, que a manipulação dos corpora só foi possivel através das ferramentas do programa computacional WordSmith Tools (Scott, 1999), o qual facilitou o levantamento das traduções.

\section{A noção de equivalência: uma breve revisão}

Em Equivalence in translation, Neubert (2004) discute não apenas as atuais divergências sobre o emprego do termo, como também os problemas que sua complexidade gera para a prática da tradução. Lembra ainda que discordâncias sobre o que de fato constituiria equivalência são muitas vezes baseadas em argumentos subjetivos vinculados à qualidade das traduções, em que uma "má tradução" é justificada por não ser equivalente ao original - ou ainda, fiel ao original. Como consequência, ressalta que o termo foi aos poucos perdendo sua potencialidade de ferramenta crítica e que, atualmente, nota-se que a equivalência não se define como um conceito puramente objetivo, mas variável de acordo com a perspectiva do tradutor e de seu específico projeto de tradução.

Ao nos voltarmos para os estudos tradutológicos, é dificil não pensar em Jakobson e em seus Aspectos linguísticos da tradução (1959). Inserido numa coletânea de textos que revelam as reflexões do autor sobre a contribuição da linguística estrutural para a teoria da comunicação, a antropologia, a literatura, a gramática, a arte da tradução e as pesquisas acerca dos distúrbios de fala, Jakobson trata, nesse texto em específico, da tradução como parte do processo de produção de significado.

Opondo-se a Saussure e baseando-se em Peirce, Jakobson afirma que, tanto "para o linguista como para o usuário comum das palavras, o significado de um signo linguístico não é mais que sua tradução por um outro signo que lhe pode ser substituído" (Jakobson, 1959:64). Por essa afirmação, podemos inferir que, para Jakobson, a principal característica do signo linguístico é o fato de ser traduzivel. Concluímos, então, que, para o linguista, cada símbolo é substituivel por outro símbolo,

TradTerm, 16, 2010, p. 313-341 
sendo tal substituição também por ele referida como recodificação ou code-switching, ou seja, a passagem de um código a outro.

Com base nesses conceitos, o linguista divide a interpretação do signo verbal em três maneiras: tradução intralingual ou reformulação, quando os signos são traduzidos a partir de outros signos da mesma língua; tradução interlingual ou tradução propriamente dita, quando se utilizam signos de outra língua; e a tradução intersemiótica, quando signos de sistemas não-verbais são usados para a interpretação primeira (Jakobson, 1959:64-65).

Tratando mais especificamente da tradução interlingual, Jakobson afirma que "a tradução envolve duas mensagens equivalentes em dois códigos diferentes", o que o leva a concluir que "a equivalência na diferença é o problema principal da linguagem e a principal preocupação da Linguística" (Jakobson, 1959:65, grifos nossos). Ao dizer mensagens equivalentes em códigos diferentes, o autor remete ao processo tradutório como uma recodificação que não altera o significado original da mensagem traduzida. Assim, o conteúdo é mantido sem alterações, havendo apenas a alteração de códigos. Pelo uso da palavra inglesa switch, em code-switching, talvez seja possivel afirmar, implicitamente, a noção de tal recodificação como um processo de reciprocidade, em que A é equivalente a B tal como B é equivalente a A. Diretamente relacionado a esse pensamento, Jakobson diz que "as linguas diferem essencialmente naquilo que devem expressar, e não naquilo que podem expressar" (idem: 69); ou seja, para ele todas as linguas podem remeter a mensagens equivalentes, porém expressas em diferentes códigos.

No mesmo ano de publicação de Aspectos linguísticos da tradução, Willard Quine apresenta seu texto Meaning and translation (1959). Apesar de basear-se em conceitos da Lógica e da Filosofia da Ciência, defende a indeterminação da tradução, tese posteriormente aprofundada na obra Word and object (1960). Diferentemente da relação de equivalência proposta por Jakobson (1959), Quine afirma que um determinado projeto de tradução só pode ser validado quando relacionado ao conjunto de hipóteses inicialmente estabelecido pelo tradutor. Assim, considerando uma segunda tradução de determinado texto, ape- 
sar de diferente da primeira, será vista como correta de acordo com a relação de hipóteses na qual foi baseada. É interessante notar, assim, como dois autores contemporâneos - embora um filósofo e outro estruturalista - lidam com a questão: enquanto um defende a indeterminação da tradução, o outro chama a atenção para a "equivalência na diferença" (Jakobson, 1959).

Nos anos 60, a discussão sobre as relações de equivalência, já presente em trabalhos anteriores - tais como Jakobson (1959) - intensificou-se, resultado de observações relacionadas à comparação dos sistemas linguísticos em questão. Nessa perspectiva, a tradução era descrita e explicada pelos estudiosos, como Mounin (1963), Nida (1964) e Catford (1965), com o intuito de buscar um possivel sistema de equivalências entre linguafonte e lingua-meta que repertoriasse as possibilidades de tradução. Conforme Neubert afirma, "a comparação de estruturas linguísticas era vista como uma maneira de oferecer a informação necessária e os procedimentos relevantes não apenas para a língua estrangeira mas também para o próprio tradutor" (Neubert, 2004:116, tradução nossa).

Considerando os trabalhos de Nida (1964) e Catford (1965), é possivel observar que ambos os autores, à maneira de Jakobson (1959), baseiam seus estudos numa concepção abstrata de equivalência segundo a qual uma tradução pode apresentar, em outro sistema linguístico, os mesmos valores do texto-fonte. Além disso, apesar de Nida (1964) e Catford (1965) basearem-se no conceito de equivalência para desenvolver suas concepções sobre tradução, não apresentam, ao longo de suas obras, uma exata definição para o termo. Assim, a fim de exemplificar seu uso nessas obras em específico, poderíamos nos estender numa apresentação que outros estudiosos já fizeram (cf. Neubert, 2004; Rodrigues, 2000). Nesse sentido, julgamos válido apenas observar que, embora o primeiro diferencie "equivalência formal" de "equivalência dinâmica" e o segundo "equivalência de tradução" de "correspondência formal", ambos os autores veem a equivalência como o centro do processo tradutório. Assim, enquanto Nida define a atividade de tradução como "a produção de mensagens equivalentes" (Nida, 1964:120, grifo nosso), Catford defende que "o problema central em prática de tradução consiste em encontrar equivalentes de tradução da LM [língua-meta]"

TradTerm, 16, 2010, p. 313-341 
(Catford, 1965:23, grifo nosso). A nosso ver, tais definições são muito próximas da de Jakobson (1959), para quem a tradução é uma recodificação que "envolve duas mensagens equivalentes em dois códigos diferentes" (Jakobson, 1959:65, grifo nosso).

$\mathrm{Na}$ década de 80, pretendendo se opor a tais formulações tradicionais, Toury (1980) julga necessário reavaliar a noção de equivalência. Segundo Rodrigues (2000), o autor busca

problematizar o conceito, mas sem questionar a própria condição de possibilidade da equivalência. Toury chega a apontar como problemático o fato de a equivalência não ser jamais definida, mas acaba por inseri-la em sua teoria como uma "equivalência teórica", ou como "equivalência máxima”. (Rodrigues, 2000:173)

Katharina Reiss, em seu ensaio "Type, kind and individuality of text: decision making in translation" (2000), apresenta uma visão funcionalista sobre a noção de equivalência na prática tradutória. Já no início do texto afirma que um dos objetivos centrais da tradução interlingual é a produção de um texto funcionalmente equivalente ao original (Reiss, 2000:160). Assim, a partir do âmbito da análise textual, apresenta diferentes fatores que incidem nesse processo de comunicação bilingue, que é, segundo a autora, mediado pelo tradutor. Reiss caracteriza tal prática como mediada, pois, para ela, o tradutor atua como um mediador entre o texto original e o traduzido, o que gera, por conseguinte, alterações intencionais ou não-intencionais na mensagem de um dado processo comunicativo.

As mudanças não-intencionais são, segundo Reiss (2000), causadas por diferenças estruturais das línguas, ou seja, são linguisticamente condicionadas. Por outro lado, as mudanças intencionais, frequentes na prática de tradução, são relacionadas a alterações na função comunicativa do texto, conduzindo não a uma equivalência funcional entre texto-fonte e texto-alvo, mas a uma reverbalização do texto original. A partir disso, Reiss conclui que, apesar de a tipologia textual ser importante para a tradução, deve-se também levar em consideração uma tipologia da tradução (Reiss, 2000:161;170). 
Segundo a autora, para se estabelecer uma tradução como um texto funcionalmente equivalente ao texto original, o tradutor deve, primeiramente, esclarecer quais as funções do texto original. De acordo com a autora, esse processo pode ser realizado em três estágios. O primeiro refere-se ao estabelecimento do tipo de texto (text type). Para Reiss, há três tipos básicos de texto: informativo (comunicação do conteúdo), expressivo (comunicação de um conteúdo artisticamente organizado) e operativo (comunicação de um conteúdo com caráter persuasivo) (Reiss, 2000:163). Apesar de esses três tipos textuais serem importantes, Reiss enaltece o tipo de texto multimidiático (multimedial text type; idem: 164) como o de maior relevância, considerando, assim, outros sistemas de signos além do linguístico. Para Reiss, quando a mensagem é verbalizada, o tipo multimidiático apresenta suas próprias especificidades, as quais também devem ser consideradas pelo tradutor. Assim, as condições extralinguísticas devem ser consideradas como a base para a tipologia midiática, de extrema relevância para a tradução.

O segundo estágio estaria ligado ao conceito de variedade textual (text variety), isto é, a uma classificação textual que varia de acordo com os padrões de uma determinada comunidade linguística. Para Reiss, o estabelecimento de tal variedade textual é de suma importância para o tradutor, uma vez que, a partir disso, diminui o risco de alterar a equivalência funcional da língua-alvo por influência das convenções da língua-fonte. Por fim, o terceiro estágio, referente ao estilo textual (Reiss, 2000:166), está relacionado à seleção dos signos linguísticos e suas possiveis combinações.

Determinadas as funções de um determinado texto a partir dos três estágios acima mencionados, pode-se dizer que, segundo Reiss, o processo de tradução pode finalmente ser iniciado. Assim, segundo a autora, enquanto a análise do tipo de texto determina o método geral de tradução, a variedade textual define as estruturas linguísticas. A partir de tal análise textual prévia, o tradutor pode então, a fim de atingir a equivalência funcional, utilizar-se de três modos de tradução: (i) que visa à preservação do conteúdo, (ii) que visa a manter a expressão artística do original, e (iii) que adapta o original à realidade da comunidade alvo a partir dos fins persuasivos requisitados na 
língua-fonte (Reiss, 2000:167-168). Para a autora, então, o processo de tradução deve ser baseado numa análise textual a fim de ser funcionalmente equivalente com o texto original.

Outra posição bastante diferente com relação à produção de mensagens equivalentes na tradução é a de Philip Lewis, em The measure of translation effects (2000). No início do ensaio, Lewis toma como base os resultados de Guillemin-Flesher (Syntaxe comparée du français et de l'anglais: problèmes de traduction) para demonstrar diferenças significativas entre o francês e o inglês. Após apontar quatro diferenças centrais, afirma que tais observações contrastivas, provenientes da comparação entre original e tradução, nos dizem muito sobre as dificuldades de traduzir do francês para o inglês. Assim, tomando como base o campo das relações enunciativas levantadas por Guillemin-Flesher, Lewis afirma que tais diferenças causam, consequentemente, inúmeros problemas de tradução, relacionados não apenas a questões puramente lexicais ou gramaticais, mas também ao fato de o enunciado traduzido não construir a mesma relação com o mundo dada inicialmente pelo original ${ }^{1}$. Para Lewis, toda a tradução resultará em algo diferente, sendo tal diferença já dada a partir da própria dissimilaridade entre as línguas (Lewis, 2000:267).

A partir dessa breve revisão sobre a noção de equivalência na tradução, pode-se notar - de Jakobson a Lewis - como o conceito é muitas vezes ambíguo, distinto ou semelhante quando comparado entre certos autores. Tal como os estudiosos Neubert (2004) e Rodrigues (2000) apresentam em seus extensos trabalhos sobre o uso do termo ao longo da história, outros pesquisadores também se preocupam com a complexidade do conceito e suas repercussões para a prática da tradução. Raymond van den Broeck (1978), por exemplo,

tomando como base as concepções de Catford, reconsidera o uso do termo, e passa a conceber a equivalência de tradução como uma equivalência de funções, como um

1 Segundo o autor, "translation, when it occurs, has to move whatever meanings it captures from the original into a framework that tend to impose a different set of discursive relations and a different construction of a reality." (Lewis, 2000:267)

TradTerm, 16, 2010, p. 313-341 
critério dinâmico e dependente de cada situação. Conclui, entretanto, que a equivalência "parece ser de natureza mais complexa do que se desejaria". (Rodrigues, 2000:24)

Nota-se, dessa forma, que o conceito de equivalência é realmente problemático e merece cuidado ao ser utilizado. Por isso, antes de partirmos para a descrição dos dicionários bilíngues português-francês e português-inglês consultados, é importante ressaltar que não vemos a tradução como geradora de unidades equivalentes, mas de correlações dinâmicas que variam de acordo com as particularidades co(n)textuais de cada forma traduzida. Assim, embora sempre haja o estabelecimento de analogias, cremos não ser possivel garantir uma dependência funcional entre original e tradução.

\section{As traduções de MAS em dicionários bilingues}

Tendo em visa a discussão sobre o conceito de equivalência no item anterior, apresentaremos, nessa seção, a descrição da marca MAS em onze obras lexicográficas bilingues, mais especificamente entre os pares de língua (I) português-francês e (II) português-inglês a fim de verificar de perto como a noção matemática de equivalência subjaz muitos desses verbetes. Notase que as lacunas de definição e contextualização intensificam a problemática.

No caso do francês, Corrêa (1973) apresenta para mas (port.) os correspondentes mais, toutefois e cependant e a locução mais encore como tradução do agrupamento mas também. Além dos correspondentes apresentados por Corrêa (1973), Valdez (2000) apresenta para mas (port.) a forma pourtant e mais com sentido de substantivo (objection, difficulté, défaut). O dicionário bilíngue francês-português/português-francês de Burtin-Vinholes (2003) apresenta para a entrada mas (port.) os correspondentes mais, cependant, toutefois e pourtante as locuções mais cependant, mais encore e au contraire para as locuções no português mas contudo, mas também e mas antes, respectivamente. Sem definição e contextualização, no entanto, o seu consulente não tem critérios suficientes para escolher o cor-

TradTerm, 16, 2010, p. 313-341 
respondente mais adequado para a sua tradução. Já o minidicionário bilíngue (francês-português/português-francês) Michaelis (1993) apresenta para as entradas mas (port.) apenas o correspondente mais (fr.). O dicionário bilingue de Azevedo (1978) indica a ocorrência de mas (port.) como nome, tal como em il y a toujours un mais, explicitando ainda as expressões mas contudo (port.) e não só... mas também (port.) e seus respectivos correspondentes, mais cependant (fr.) e non seulement... mais encore (fr.). Por ser produto do resumo do dicionário de Azevedo (1978), Rousé \& Cardoso (1986) não realizam qualquer alteração no verbete de mas nos dicionários "Bertrand". Florenzano (s/d), numa tentativa de realizar uma seleção dos vocábulos mais usados em português e em francês, apresenta para mas (port.) somente o correspondente mais (fr.).

Passando para o inglês, o dicionário Novo Michaelis (1986) traz para mas (port.) seu uso como substantivo, advérbio e conjunção. No primeiro caso, apresenta as significações de objeção, restrição, obstáculo e erro sem qualquer exemplificação para sua compreensão. No caso do uso como advérbio, apresenta apenas as formas indeed e yes como possibilidades. O dicionário amplia os correspondentes somente para o uso como conjunção, apresentando as marcas but, only, however, still, yet e even como traduções possiveis. Em seguida, traz os exemplos: mas claro! / why yes!, não só vadio mas também malcriado / not only lazy but also ill-mannered, nem mas nem meio mas / but me no buts! e, por último, sempre tens um mas para meus desejos / you always have a but to set against my wishes. É interessante notar que o verbete de mas (port.) no Michaelis - Dicionário Prático inglês-português/português-inglês, publicado pelo jornal Folha da Tarde em 1995, possui o mesmo conteúdo que o de 1986. Já o dicionário bilíngue português-inglês/inglês-português Oxford Escolar (2005), por exemplo, apresenta para a entrada mas (port.) sua classificação como conjunção e apenas o item but (ing.) como correspondente, indicando a seguinte sentença como exemplo: devagar mas com segurança / slowly but surely.

Através dos verbetes acima descritos, um consulente certamente teria dificuldades na escolha do correspondente mais coerente para o contexto exigido na língua-fonte. Além disso, sem uma descrição de suas diferenças, poderia inferir que os 
correspondentes são equivalentes, no sentido de serem substituiveis entre si em quaisquer contextos. Apesar de em alguns casos - i.e. Burtin-Vinholes (2003), para o francês, e Novo Michaelis (1986), para o inglês - termos certa variedade tradutológica, incluindo agrupamentos ou expressões, percebe-se que não há reflexão sobre o uso de cada uma das formas apresentadas. Assim, questões sintático-pragmáticas, por exemplo, não são levadas em consideração. No entanto, são muitas as particularidades de pontuação, posicionamento e registro entre uma lingua e outra, que unidades gramaticais, tal como as lexicais, também trazem em sua definição. Além disso, não podemos nos esquecer que, intrinsecamente ligada ao ato tradutório, está a interface entre língua e cultura. Mesmo quando se traduz marcas gramaticais, temos de considerar que cada sistema cultural não apenas condiciona a visão de mundo do homem como também possui a sua própria lógica (Laraia, 2008). É nessa problemática que a tradução se encaixa, já que o tradutor, por mais que esteja inserido na cultura da lingua-alvo, tem suas raízes em outra realidade cultural.

Vale notar, desse modo, a intrigante tarefa do pesquisador em encontrar os traços linguísticos que revelam tais visões desencontradas de mundo na relação entre o texto-fonte e o texto-alvo, fatores essenciais para elaboração de verbetes bilíngues ${ }^{2}$. Assim, tal como veremos a seguir, mesmo a busca por correspondentes tradutórios gramaticais não pode isolar-se do contexto situacional empregado, que caracteriza, na primeira ou na segunda língua, variações de ordem cultural que devem ser levadas em consideração.

2 É importante ressaltar que nossa preocupação com a elaboração de verbetes bilingues gramaticais deve-se ao fato de este trabalho ser um recorte de nossa pesquisa de mestrado, iniciada em 2009: Um estudo de marcas adversativas do português à luz de uma abordagem lexicográfica bilingue diferencial (português-francês e português-inglês): o caso de mas, porém, contudo, todavia e entretanto (apoio FAPESP - proc. 2008/56075-0).

TradTerm, 16, 2010, p. 313-341 


\section{Linguística de Corpus e tradução}

Olohan (2004) e Halliday \& Teubert \& Giermáková (2004) apresentam a Linguística de Corpus como uma área que vem se destacando como uma fonte de recursos computacionais aplicáveis tanto à prática da tradução quanto a análises do processo tradutório. Um importante conceito da Linguística de Corpus associado à Tradutologia é a definição de corpora paralelos que, segundo Halliday, Teubert, Yallop \& Germáková (2004), são aqueles que apresentam textos correspondentes e normalmente alinhados em duas ou mais linguas. A tecnologia, assim, é extremamente importante para essa abordagem, já que os computadores são muito úteis, com ferramentas indispensáveis usadas nesse processo.

No caso de nossa pesquisa, o estudo das traduções de MAS só foi possivel a partir do programa computacional WordSmith Tools (Scott, 1999), pelo qual repertoriamos as estratégias tradutórias (Aubert, 1998) empregadas no corpus paralelo selecionado. Assim, considerando nossa preocupação com a relação entre língua e cultura, decidimos analisar, neste trabalho, as traduções para o (I) francês e o (II) inglês da obra Onde andara Dulce Veiga (1991), de Caio Fernando Abreu - (I) Qu'est devenue Dulce Veiga? (1994), traduzida por Claire Cayron -e (II) Whatever happened to Dulce Veiga? (2000), traduzida por Adria Frizzi.

O alinhamento de nossos corpora paralelos foi realizado através do utilitário Aligner do programa WordSmith Tools, o qual nos permitiu obter os paralelos entre original e tradução. Considerando a problemática da lexicografia bilíngue (Zavaglia, 2008), essa ferramenta da Linguística de Corpus teve um papel muito importante em nossa pesquisa, já que nos trouxe a simultânea co(n)textualização da marca que desejamos estudar, tanto na língua-fonte quanto na língua-alvo. Assim, obtivemos, através de co(n)textos específicos, os correspondentes tradutórios para o francês e o inglês para cada uma das 289 ocorrências de MAS encontradas no corpus monolíngue - ou seja, a obra original em português.

Esse dado foi levantado por outra ferramenta do programa

- Wordlist-, que trouxe os dados estatísticos do corpus ${ }^{3}$. Tratan-

3 De acordo com a ferramenta Wordlist, o corpus selecionado apresenta 60.510 tokens e 9.231 types, sendo a relação type-token ratio de 15,26.

TRADTERm, 16, 2010, p. 313-341 
do especificamente do utilitário Aligner, pudemos observar os paralelismos entre original e tradução, de modo que os textos foram simultaneamente apresentados da seguinte maneira:

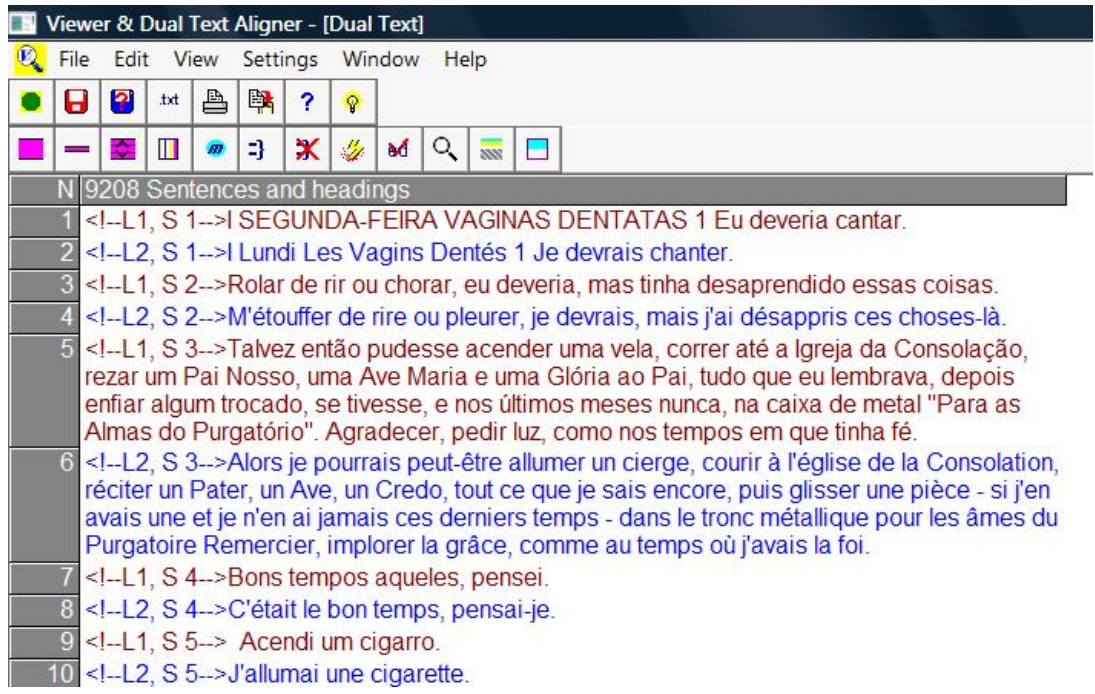

Figura 1: Alinhamento do corpus paralelo português-francês

A figura 1 refere-se ao corpus paralelo português-francês. Vale notar que, para trabalhar com tal ferramenta, deve-se ter os arquivos dos dois textos em formato .txt, pois é somente nessa extensão que o programa WordSmith Tools lê os arquivos. Assim, ressaltamos a fase de digitalização e revisão das obras, fato essencial para o estabelecimento dos corpora. Em seguida, dentro do item Tools (Ferramentas), encontra-se o acesso aos Utilities (Utilitários), que contêm o Viewer \& Aligner (Visualizador e Alinhador). Selecionando-o, abre-se uma nova janela onde se deve escolher o item File (Pasta). Ali, encontra-se o utilitário Aligner, que permite a visualização dos textos alinhados. Basta escolher o texto-fonte, que aparece em vermelho e, em seguida,

MAS possui uma frequência relativa de $0,50 \%$, sendo a $24^{a}$ unidade mais frequente em todo o corpus monolingue.

TradTerm, 16, 2010, p. 313-341 
a sua tradução, que aparece em azul, para poder analisar os trechos em paralelo. Com base no alinhamento, demonstraremos, a seguir, a análise das traduções de MAS para o francês e o inglês, de acordo com as modalidades tradutórias de Aubert (1998).

\section{A análise das traduções à luz das modalidades de Aubert} (1998)

Para a análise das relações tradutológicas entre a marca MAS em português e suas traduções para o francês e para o inglês, utilizamos as "modalidades de tradução" de Aubert (1998), que se voltam principalmente para os diversos fatores que incidem sobre as estratégias utilizadas pelo tradutor no ato tradutório. Antes de detalharmos a análise dos resultados, vale notar os correspondentes encontrados para MAS em nosso corpus paralelo:

\begin{tabular}{c|c|c|c}
\hline $\begin{array}{c}\text { Correspondentes } \\
\text { tradutórios para } \\
\text { MAS em francês }\end{array}$ & $\begin{array}{c}\text { Número de } \\
\text { ocorrências }\end{array}$ & $\begin{array}{c}\text { Correspondentes } \\
\text { tradutórios para MAS } \\
\text { em inglês }\end{array}$ & $\begin{array}{c}\text { Número de } \\
\text { ocorrências }\end{array}$ \\
\hline mais & 256 & but & 263 \\
\hline$\varnothing^{4}$ & 15 & $\varnothing$ & 15 \\
\hline et & 3 & and & 2 \\
\hline pourtant & 2 & although & 2 \\
\hline plutôt & 2 & then & 2 \\
\hline alors & 2 & though & 1 \\
\hline sauf & 1 & what about & 1 \\
\hline quand & 1 & so & 1 \\
\hline que & 1 & when & 1 \\
\hline même & 1 & & \\
\hline pas & 1 & & \\
\hline lorsque & 1 & & \\
\hline et aussi & 1 & & \\
\hline malgré & 1 & & \\
\hline au fait & 1 & & \\
\hline Total & $\mathbf{2 8 9}$ & Total & \\
\hline \multicolumn{2}{|r|}{} & & \\
\hline
\end{tabular}

Tabela 1: Possibilidades tradutórias encontradas para MAS no corpus paralelo português-francês e português-inglês

4 Este símbolo indica que não houve correspondentes diretos encontrados nas traduções. 
Apesar de os correspondentes MAIS (em francês) e BUT (em inglês) serem de fato muito mais frequentes que as demais unidades, não podemos desconsiderar todas as outras possibilidades encontradas. Assim, pela tabela 1, podemos notar que a tradução francesa analisada possui uma variação tradutológica maior que a tradução em inglês, apresentando 33 variações contra 25 da língua inglesa ${ }^{5}$. Além disso, é interessante observar que ambas as traduções - para o francês e o inglês - apresentaram o mesmo número de casos em que não houve correspondente direto de MAS na língua-alvo. Em busca das relações tradutológicas entre os itens acima, discutiremos os resultados a partir de Aubert (1998).

Segundo o autor, as modalidades se organizam da seguinte maneira: (1) omissão, quando uma parte do texto fonte é suprimida e não é recuperável através da tradução, devendo-se recorrer ao texto original para ter acesso à informação suprimida; (2) espelhamento, quando há a reocorrência de um determinado trecho do original no texto fonte com mudanças zero, desdobrando-se em (2a) transcrição, quando certo segmento é comum às duas língua em questão e é portanto reproduzido identicamente na tradução (algarismos e latinismos, por exemplo), (2b) empréstimo, quando algo específico da língua de partida é mantido na lingua de chegada, identificado por nota de rodapé ou aspectos visuais, e em (2c) decalque, quando tenta-se, na tradução, resgatar a pronúncia da língua fonte de acordo com as regras da língua alvo; (3) literalidade, quando não há interferências que impeçam o andamento linear do processo tradutório, dividindo-se em (3a) tradução palavra por palavra, quando, ao

5 É preciso ressaltar que este artigo não pretende generalizar as relações tradutológicas entre português-francês e português-inglês apenas com os dados aqui apresentados. Graças aos expedientes da linguística de corpus, pretendemos, por outro lado, chamar atenção para a problemática noção de equivalência prototípica entre unidades gramaticais, no caso, a marca MAS do português brasileiro e suas traduções para o francês e o inglês. Vale lembrar, ainda, que este trabalho pertence um projeto de pesquisa maior, em nivel de mestrado (cf. Nota 2), onde discutimos as relações tradutológicas em questão de modo mais aprofundado.

TradTerm, 16, 2010, p. 313-341 
comparar o trecho original com o traduzido verifica-se o mesmo número de palavras, a mesma ordem sintática e a não ocorrência de mudança de categoria, em (3b) transposição, quando o tradutor recorre a ajustes morfossintáticos para se adequar à gramática da língua meta, e em (3c) explicitação, quando se explicita uma informação que está implícita no original; (4) equivalência, quando o grau de visibilidade da atuação do tradutor é maior, desdobrando-se em (4a) implicitação, quando alguma informação é condensada a fim de facilitar o entendimento do leitor da língua alvo, em (4b) modulação, quando temos a mudança de ponto de vista devido aos idiomatismos de expressão, por exemplo, e em (4c) adaptação, quando ocorre adaptação cultural de certo segmento para a língua fonte; (4d) tradução intersemiótica, quando ocorre o diálogo entre diferentes tipos de linguagem, como entre um texto escrito e uma determinada ilustração; e, finalmente, (5) erro, quando há, na passagem de uma língua para outra, uma real troca de sentidos.

Através da observação das traduções, não encontramos, em nenhuma das direções, casos de erro nem espelhamento. A literalidade, por outro lado, foi a mais recorrente, com muitas ocorrências de tradução palavra por palavra e transposição. Em seguida, tivemos como mais recorrente a estratégia de omissão e, por fim, a de equivalência, com a modulação.

\begin{tabular}{|c|c|c|c|c|c|}
\hline \multicolumn{3}{|c|}{ Português-francês } & \multicolumn{3}{|c|}{ Português-inglês } \\
\hline $\begin{array}{l}\text { Traduções } \\
\text { para MAS }\end{array}$ & Modalidade & $\mathbf{n}$ & $\begin{array}{c}\text { Traduçõe } \\
\text { s para } \\
\text { MAS }\end{array}$ & Modalidade & $\mathbf{n}$ \\
\hline Mais & Palavra por palavra & 197 & But & Palavra por palavra & 249 \\
\hline Mais & Transposição & 59 & But & Transposição & 15 \\
\hline$\varnothing$ & Omissão & 14 & $\varnothing$ & Omissão & 13 \\
\hline$\varnothing$ & Omissão + Modulação & 1 & $\varnothing$ & Omissão + Modulação & 2 \\
\hline Et & Palavra por palavra & 1 & And & Transposição & 1 \\
\hline Et & Modulação & 1 & And & $\begin{array}{c}\text { Transposição + } \\
\text { Modulação }\end{array}$ & 1 \\
\hline Et & $\begin{array}{c}\text { Transposição + } \\
\text { Modulação }\end{array}$ & 1 & Then & $\begin{array}{c}\text { Transposição + } \\
\text { Modulação }\end{array}$ & 2 \\
\hline Pourtant & Palavra por palavra & 2 & Although & Palavra por palavra & 2 \\
\hline Plutôt & Modulação & 2 & Though & Palavra por palavra & 1 \\
\hline Alors & Modulação & 2 & $\begin{array}{l}\text { What } \\
\text { About }\end{array}$ & Modulação & 1 \\
\hline Pas & Modulação & 1 & So & $\begin{array}{c}\text { Transposição + } \\
\text { Modulação }\end{array}$ & 1 \\
\hline
\end{tabular}




\begin{tabular}{|c|c|c|c|c|c|}
\hline Pas & Modulação & 1 & So & $\begin{array}{c}\text { Transposição + } \\
\text { Modulação }\end{array}$ & 1 \\
\hline Sauf & Transposição & 1 & When & $\begin{array}{c}\text { Transposição }+ \\
\text { Modulação }\end{array}$ & 1 \\
\hline Que & Transposição & 1 & & & \\
\hline Même & Transposição & 1 & & & \\
\hline Malgré & Transposição & 1 & & & \\
\hline Au fait & Transposição & 1 & & & \\
\hline Lorsque & $\begin{array}{c}\text { Transposição }+ \\
\text { Modulação }\end{array}$ & 1 & & & \\
\hline Et aussi & $\begin{array}{c}\text { Transposição }+ \\
\text { Modulação }\end{array}$ & 1 & & & $\mathbf{2 8 9}$ \\
\hline Quand & $\begin{array}{c}\text { Transposição }+ \\
\text { Modulação }\end{array}$ & 1 & & & \\
\hline Total & & $\mathbf{2 8 9}$ & Total & & \\
\hline
\end{tabular}

Quadro 1: As traduções de MAS para o francês e o inglês à luz das modalidades de Aubert (1998)

Para analisar os dados acima, vale relembrar que, de acordo com Aubert (1998), as modalidades tradução palavra por palavra e transposição são observadas quando não há interferências que impeçam o andamento linear do processo tradutório. Mas, enquanto na primeira verifica-se o mesmo número de palavras, a mesma ordem sintática e a não ocorrência de mudança de categoria, na segunda, nota-se que o tradutor teve de recorrer a ajustes morfossintáticos para se adequar à gramática da lingua-meta. Assim, como a transposição se constitui em co(n)textos tradutórios em que o sentido é mantido, mas mudanças de categoria, de número de palavras e de posicionamento podem ocorrer, é muito provável que na tradução de itens gramaticais uma dessas variantes ocorra. Por esse motivo, é possivel compreender o alto número de transposições em nosso corpus paralelo - tanto para o francês quanto para o inglês.

Abaixo, temos um exemplo de MAS traduzido por MAIS (em francês) e BUT (em inglês) por meio da modalidade tradução palavra por palavra, em meio de enunciado:

(01) Acontecera um milagre. Um milagre à toa, MAS básico para quem, como eu, não tinha pais ricos, dinheiro aplicado, imóveis nem herança e apenas tentava viver sozinho numa cidade infernal como aquela que trepidava lá fora, além da janela ainda fechada do apartamento.

TradTerm, 16, 2010, p. 313-341 
(02) Un miracle avait eu lieu. Un drôle de miracle, MAIS capital pour quelqu'un qui, comme moi, n'avait pas une riche famille, de l'argent placé, des biens immeubles ou un héritage et ne faisait que tenter de vivre dans une ville infernale comme celle qui bourdonnait dehors, au-delà de la fenêtre encore fermée de l'appartement.

(03) A miracle had occurred. A modest miracle, BUT essential to someone who, like me, didn't have rich parents, investments, real estate, or inheritance and was just trying to make it on his own in an infernal city like the one throbbing outside my still unopened apartment window.

Nos trechos a seguir, temos, para os mesmos correspondentes, casos da modalidade transposição. Vale notar que, dos 15 casos em que BUT foi traduzido pela transposição, 10 deles foram alvos da mesma estratégia no francês. Eis um exemplo:

(01) Dulce não se movia. Delicado então, MAS firme, ele começou a me empurrar em direção à porta, dizendo que voltasse depois, outro dia, que tinha pressa, precisava viajar, que Dulce não estava bem, que não havia tempo, nem um minuto, ele precisava viajar, fugir, urgente.

(02) Dulce ne bougeait pas. Doucement MAIS fermement, Il s'est mis alors à me pousser vers la porte en me disant de revenier, un autre jour, qu'il était pressé, qu'il devait partir en voyage, que Dulce n'allait pas bien, qu'il n'avait pas le temps, pas une minute, qu'il lui fallait partir, s'enfuir, d'urgence.

(03) Dulce didn't move. Then, gently BUT firmly, he began to push me toward the door, telling me to come back later, some other day, that he was in a hurry, he was going to travel, that Dulce wasn't feeling well, that there was no time, not even a minute, and he needed to leave, flee, urgently.

Aqui e no próximo exemplo, apresentamos as traduções de MAS sem correspondente direto, em que a unidade não é recuperável através da tradução. Iniciamos com a omissão + modulação ${ }^{6}$ :

6 Os trechos de omissão constam em negrito para facilitar a identificação do leitor.

TradTerm, 16, 2010, p. 313-341 
(01) - Não foi sobre a novela que vim falar com a senhora.

- Ah, não? - ela estava surpresa. - MAS me chama de você, por favor.

- É sobre uma pessoa que você conheceu. - Fala, meu bem.

- Dulce Veiga - eu disse.

(02) - C'est n'est pas du feuilleton que je suis venir vous parler, madame.

- Ah non? - elle était surprise. - Pas de madame entre nous s'il vous plaît.

- C'est de quelqu'un que vous avez connu.

- Dites, mon chou.

- Dulce Veiga, dis-je.

(03) "I didn't come to talk to you about the soap, Miss Lara."

"You didn't?" She looked surprised. "Call me Lilian, please." "It's about someone you knew once, Lilian."

"Go on, darling."

"Dulce Veiga," I said.

Consideramos o trecho acima como omissão+modulação, pois cremos que, além de a unidade MAS ter sido omitida, houve mudança de ponto de vista na tradução. Tal processo não ocorreu na passagem seguinte, em que houve apenas a omissão. Para facilitar a exemplificação, selecionamos um trecho em que, para o mesmo original, tivemos a mesma modalidade para ambas as traduções:

(01) Eu perguntei:

- MAS o que você quer, afinal?

Ela sorriu:

- Além de cantar?

- Mais além.

- Nada além: eu quero encontrar outra coisa.

(02) Je demandai :

- Que cherchez-vous, finalement?

Elle sourit :

- Au-delà de chanter?

- Bien au-delà.

- Au de-là rien : je veux juste trouver autre chose.

(03) I asked:

TradTerm, 16, 2010, p. 313-341 
"What is it that you want, anyway?"

She smiled:

"Besides singing?"

"Besides that."

"Nothing more: I want to find something else."

Através da análise comparativa das traduções, notamos que, em muitos casos, tivemos, a partir do mesmo trecho original, a mesma modalidade para ambas as línguas. Além dos quatro exemplos acima, é interessante notar esse caso de transposição + modulação:

(01) Não havia ninguém à vista. Tive vontade de entrar por aquele corredor, MAS lembrei de Patrícia.

(02) Personne en vu. J'allais entrer dans le couloir LORSQUE je me souvins de Patricia.

(03) There was nobody in sight. I wanted to go down that hallway, THEN I remembered Patrícia.

Na seção de anexos, além das relações tradutológicas citadas acima, constam todas as outras possibilidades tradutórias encontradas em nosso corpus paralelo (cf. Quadro 2 e Quadro 3). Em forma de tabelas, trazemos as traduções para o francês e o inglês, seguidas da respectiva modalidade e contexto em que foram encontradas.

\section{Considerações finais}

Considerando nosso corpus de estudo, vimos que, devido às relações interlinguísticas e ao caráter transcategorial das palavras, MAS em português não terá como correspondente, em francês ou em inglês, necessariamente uma conjunção coordenativa adversativa, assim habitualmente definida. Dependendo de fatores semânticos, contextuais, estruturais, estilísticos etc., poderemos ter, como possibilidades tradutórias, plutôt (fr.) e what about (ing.), por exemplo. Além disso, tal como exemplificado acima, há casos em que MAS é omitido, havendo, assim, uma supressão de parte do texto fonte.

TRadTerm, 16, 2010, p. 313-341 
É possivel afirmar, desse modo, que, a partir do corpus paralelo observado, não é somente considerável a variação tradutológica de MAS - tanto em francês quanto em inglês - como também cada tradução apresenta particularidades interessantes, fato corroborado pelo alto índice de transposições - e modulações - em nossos corpora.

É nesse contexto que o estudo contrastivo, a partir de corpora paralelos, torna-se interessante para a análise semântico-tradutológica de uma dada lexia. Tendo em vista a falta de estudos de palavras ditas gramaticais como realmente significantes - ou seja, com significação, assim como as palavras lexicais - e a importância dessas marcas na organização lógico-discursiva dos textos, procuramos, neste trabalho, chamar a atenção para a complexa noção de equivalência nos estudos da tradução e mostrar, através de exemplos da lexicografia bilíngue (português-francês e português-inglês), como a visão matemática do termo influencia as descrições da marca gramatical MAS em verbetes bilíngues tradicionais.

\section{Agradecimentos}

À Professora Tinka Reichmann e à minha orientadora, Professora Adriana Zavaglia, pelas instigantes discussões durante o curso de Pós-Graduação "Estudos da Tradução: diferentes abordagens e perspectivas" ( $\left.1^{\circ} \mathrm{sem} / 2009\right)$, essenciais para a elaboração deste artigo.

\section{Referências bibliográficas}

ABREU, C. F. (1991) Onde andara Dulce Veiga. São Paulo: Companhia das Letras.

(1994) Qu'est devenue Dulce Veiga? Paris: Éditions Autrement, Tradução de Claire Cayron.

(2000) Whatever happened to Dulce Veiga? A B-Novel. Texas:

University of Texas Press. (Texas Pan American series). Trad. Adria Frizzi.

AUBERT, F. H. (1998) Modalidades de tradução: teoria e resultados. TradTerm. São Paulo: Humanitas n. 1, pp. 99-128.

TradTerm, 16, 2010, p. 313-341 
AZEVEDO, D. (1978) Grande dicionário francês - português, português - francês. Lisboa: Livraria Bertrand.

BERBER SARDINHA, T. (2004) Linguistica de Corpus. São Paulo: Manole. BURTIN-VINHOLES, S. (2003) Dicionário francês-português, portuguêsfrancês / S. Burtin-Vinholes com a colab. de Laurence Curtenaz e Maria José Nonnenberg. 40. ed. São Paulo: Globo.

CATFORD, J. C. (1980) Uma teoria linguística da tradução: um ensaio em linguística aplicada. São Paulo: Cultrix, Tradução do Centro de Especialização de Tradutores de Inglês do Instituto de Letras da Pontifícia Universidade Católica de Campinas.

CORRÊA, R. A. (1973) Dicionário escolar francês-português, portuguêsfrancês. Rio de Janeiro: Mec. 5a. ed.

FLORENZANO, E. (19-) Dicionário Ediouro francês-português, português-francês. Rio de Janeiro: Ediouro, 17a. ed.

HALLIDAY, M. A. K.; TEUBERT, W.; YALLOP, C.; GERMÁKOVÁ, A. (2004) Lexicology and Corpus Linguistics. Londres: Continuum.

JAKOBSON, R. (1995 [1959]) Aspectos linguísticos da tradução. Linguística e comunicação. São Paulo: Cultrix. Trad. Izidoro Blikstein e José Paulo Paes, pp. 63-72.

LARAIA, R. B. (2008) Cultura: um conceito antropológico. Rio de Janeiro: Jorge Zahar, $22^{a}$ ed.

LEWIS, P. (2000) The Measure of Translation effects. In: VENUTI, L. (org). The Translation Studies Reader. London: Routledge, pp. 264-283.

MICHAELIS (1995) Dicionário Prático Inglês-Português/Português-Inglês. São Paulo: Empresa Folha da Tarde da Manhã S. A.

MOUNIN, G. (1975 [1963]) Os problemas teóricos da tradução. São Paulo, Cultrix. Trad. Heloísa de Lima Dantas.

MUNDAY, J. (2005) Translation theory before the twentieth century. Introducing Translation Studies. Theories and Applications. New York: Routledge, pp. 18-34.

NEUBERT, A. (2004) Equivalence in translation. In: KITTEL et al. (eds.) Übersetzung - Translation - Traduction. Ein internationales Handbuch zur Übersetzungsforschung / An International Encyclopedia of Translation Studies / Encyclopédie internationale de la recherche sur la traduction, tomo $1, \mathrm{n}^{\circ} 36$, New York: Walter de Gruyter. Colunas 622-646.

NIDA, E. A. (1964) Toward a science of translating. Netherlands: E. J. Brill. 
NOVO MICHAELIS (1986) Dicionário Prático Inglês-Português/Português-Inglês. São Paulo: Melhoramentos.

OLOHAN, M. (2004) Introducing Corpora in Translation Studies. Londres: Routledge.

OXFORD ESCOLAR (2005) Português-inglês/inglês português para estudantes brasileiros.

PEREIRA, H. B. C.; SIGNER, R. (1993) Michaelis: minidicionário francês-português, português-francês. São Paulo: Melhoramentos.

QUINE, W. V. O. (2000) Meaning and Translation. In: VENUTI, L. (org.). The Translation Studies Reader. London: Routledge, pp. 94-111.

REISS, K. (2000) Type, Kind and Individuality of Text: Decision Making in Translation. In: VENUTI, L. (org.). The Translation Studies Reader. London: Routledge, pp. 160-71.

RODRIGUES, C. C. (2000) Tradução e diferença. São Paulo: Editora UNESP.

ROUSÉ, J.; CARDOSO, E. (1986) Dictionnaires Bertrand: portugaisfrançais. Venda Nova: Bertrand.

TOURY, G. (1980) In search of a theory of translation. Tel Aviv: Porter Institute.

VALDEZ, J. F. (2000) Dicionário francês-português português-francês. Rio de Janeiro: Livraria Garnier.

ZAVAGLIA, A. (2008) Apresentação das bases do dicionário relacional (português-francês) - DIRE. In: OLIVEIRA, A. M. P. P.; ISQUERDO, A. N. (orgs.) As ciências do léxico: lexicologia, lexicografia e terminologia. Campo Grande: Ed. UFMS, pp. 233-253.

TradTerm, 16, 2010, p. 313-341 
ANEXOS

Quadro 2: As traduções de MAS para o francês

\begin{tabular}{|c|c|c|c|}
\hline $\begin{array}{c}\text { Corres- } \\
\text { pondente }\end{array}$ & Modalidade & Original em português & Tradução em francês \\
\hline Et & $\begin{array}{l}\text { Palavra por } \\
\text { palavra }\end{array}$ & $\begin{array}{l}\text { O baixinho do espelho me empurrou } \\
\text { para fora. Eu estava atordoado } \\
\text { demais para reagir, me deixei levar. } \\
\text { Para fora, para longe, para qualquer } \\
\text { lugar, } \\
\text { talvez lá onde estavam a poltrona } \\
\text { verde, a seringa manchada de sangue, } \\
\text { o berço no canto escuro. Não sei } \\
\text { como tinha esquecido tudo aquilo, } \\
\text { MAS agora também não sabia o jeito } \\
\text { certo, se havia um, de lembrar. } \\
\text { Tantas coisas, tantos anos depois de } \\
\text { Dulce Veiga. }\end{array}$ & $\begin{array}{l}\text { L'avorton au miroir me poussa } \\
\text { dehors. J'étais trop étourdi pour } \\
\text { réagir, et me laissai pousser. Dehors, } \\
\text { loin, vers n'importe où, peut-être là } \\
\text { où étaient le fauteuil vert, la seringue } \\
\text { tachée de sang, le berceau dans un } \\
\text { coin sombre. Comment avais-je pu } \\
\text { oublier tout cela, ET à présent par } \\
\text { quel moyen, s'il en était un, m'en } \\
\text { souvenir? Tant de choses, tant } \\
\text { d'années, avaient passé après Dulce } \\
\text { Veiga. }\end{array}$ \\
\hline Et & Modulação & $\begin{array}{l}\text { MAS Saul, eu perguntara, quem é } \\
\text { Saul. E Alberto, como Márcia, não } \\
\text { lembrava de ninguém com esse } \\
\text { nome. }\end{array}$ & $\begin{array}{l}\text { ET Saul, me demandai-je, qui est } \\
\text { Saul. Alberto, comme Marcia, ne se } \\
\text { souvenait de personne portant ce } \\
\text { nom. }\end{array}$ \\
\hline Et & $\begin{array}{l}\text { Transposição } \\
+ \text { Modulação }\end{array}$ & $\begin{array}{l}\text { Embaixo delas, a terra arfava feito } \\
\text { um gato feliz. Curvei-me para ouvir a } \\
\text { terra, MAS levantei assustado com } \\
\text { uma forma viva enorme na minha } \\
\text { frente. Um homem, um animal, } \\
\text { pensei - era uma árvore. }\end{array}$ & $\begin{array}{l}\text { Dessous, la terre ronronnait comme } \\
\text { um chat heureux. Je me penchai pour } \\
\text { l'entendre ET me relevai, effrayé par } \\
\text { une forme vivante, énorme, en face } \\
\text { de moi. Un homme, un animal, } \\
\text { pensai-je - c'estait un arbre. }\end{array}$ \\
\hline \multirow[t]{2}{*}{ Pourtant } & \multirow[t]{2}{*}{$\begin{array}{l}\text { Palavra por } \\
\text { palavra }\end{array}$} & $\begin{array}{l}\text {-- Meu filho, os caminhos estão } \\
\text { muito mais abertos do que você } \\
\text { imagina. Só que eles parecem tortos. } \\
\text { MAS é por esses caminhos que } \\
\text { parecem tortos que você tem que } \\
\text { caminhar, e as coisas vêm ao seu } \\
\text { encontro. Você só tem que escutar os } \\
\text { caminhos e seguir por eles. }\end{array}$ & $\begin{array}{l}\text {-- Mon fils, les chemins sont plus } \\
\text { ouverts que tu le penses. Mais ils ont } \\
\text { l'air tordus. POURTANT c'est par } \\
\text { ses chemins apparemment tordus que } \\
\text { tu doit cheminer, et les choses } \\
\text { viendront à ta rencontre. Tu n'as qu'a } \\
\text { écouter les chemins et les suivre. }\end{array}$ \\
\hline & & $\begin{array}{l}\text {-- Para você, é seu aniversário. Este } \\
\text { é o Cazuza, cuide bem do príncipe. } \\
\text { MAS nem contei nada, pensei. }\end{array}$ & $\begin{array}{l}\text {-- C'est pour vous, pour votre } \\
\text { anniversaire. Celui-là s'appelle } \\
\text { Cazuza, prenez bien soin du petit } \\
\text { prince. } \\
\text { POURTANT je ne lui ai rien dit, } \\
\text { pensai-je. }\end{array}$ \\
\hline
\end{tabular}

TradTerm, 16, 2010, p. 313-341 


\begin{tabular}{|c|c|c|c|}
\hline & & $\begin{array}{l}\text { Ele gritou. Não era um grito, MAS } \\
\text { um grunhido, um roncosem forma, } \\
\text { como se a dor não encontrasse } \\
\text { palavras. }\end{array}$ & $\begin{array}{l}\text { Il cria. Non, pas un cri, PLUTÔT un } \\
\text { grognement, un râle informe, comme } \\
\text { si la douler ne trouvait pas des mots. }\end{array}$ \\
\hline Plutôt & Modulação & $\begin{array}{l}\text { Eu bebi. Como se tivesse cola, visgo, } \\
\text { o líquido escorregou com dificuldade } \\
\text { pela garganta. Fechei os olhos, e senti } \\
\text { os dedos de Dulce Veiga fazendo o } \\
\text { sinal-da-cruz na minha testa. Não } \\
\text { como se eu morresse, MAS feito uma } \\
\text { bênção, batismo. O gosto amargo } \\
\text { permanecia na boca. }\end{array}$ & $\begin{array}{l}\text { Je bus. Comme s'il contenait de la } \\
\text { colle, quelque chose de gluant, le } \\
\text { liquide glissat avec difficulté dans } \\
\text { ma gorge. Je fermai les yeux, sentis } \\
\text { les doigts de Dulce Veiga faire un } \\
\text { signe de croix sur mon front. Pas } \\
\text { comme si j’étais mort, PLUTÔT } \\
\text { comme une bénédiction, un baptême. } \\
\text { Ma boûche gardait un goût amer. }\end{array}$ \\
\hline Alors & Modulação & $\begin{array}{l}\text { A casa não ficava no Morumbi, } \\
\text { Jardins ou qualquer outro desses } \\
\text { bairros chiques. Depois de voltas e } \\
\text { voltas, consultas num guia em } \\
\text { pedaços onde as ruas sempre } \\
\text { continuavam justamente nas páginas } \\
\text { que estavam faltando, perguntas nas } \\
\text { esquinas e informações do tipo conta } \\
\text { três faróis, MAS só existiam dois, } \\
\text { vire depois à esquerda, mas à } \\
\text { esquerda não havia rua alguma, o } \\
\text { motorista do táxi conseguiu encontrar } \\
\text { um pequeno sobrado no alto da } \\
\text { Freguesia do Ó. Paguei sem } \\
\text { reclamar, dinheiro do jornal. }\end{array}$ & $\begin{array}{l}\text { La Maison ne se trouvait pás à } \\
\text { Morumbi, à Jardin ou quelque autre } \\
\text { quartier chic. Après tours et détours, } \\
\text { la consultation d'un guide en } \\
\text { morceaux où le plan de rues se } \\
\text { continuait justement sur les pages } \\
\text { manquantes, après des questions aux } \\
\text { carrefours et des indications du type } \\
\text { comptez trois feux ALORS qu'il n'y } \\
\text { en avait que deux, tournez à gauche } \\
\text { mais à gauche il n'y avait pas de rue, } \\
\text { le chauffer de taxi réussit a trouver } \\
\text { une maison à étage sur les hauteurs } \\
\text { de Freguesia do Ó. }\end{array}$ \\
\hline & & $\begin{array}{l}\text { MAS o pai não era Oxóssi, pensei em } \\
\text { perguntar. }\end{array}$ & $\begin{array}{l}\text { ALORS son père n'èstait Oxossí ? } \\
\text { fus-je sur le point de demander. }\end{array}$ \\
\hline Pas & Modulação & $\begin{array}{l}\text { Samambaias verdejantes } \\
\text { despencavam em cascatas no jardim } \\
\text { suspenso, MAS insuficientes para } \\
\text { ocultar o grafite no muro daquele } \\
\text { bolo de cimento coberto de antenas } \\
\text { parabólicas. }\end{array}$ & $\begin{array}{l}\text { Des samambaias verdoyantes } \\
\text { croulaient en cascade dans le jardin } \\
\text { suspendu, PAS assez pour cacher un } \\
\text { graffiti sur le mur de cette pâtisserie } \\
\text { en ciment chargée d'antennes } \\
\text { paraboliques. }\end{array}$ \\
\hline Sauf & Transposição & $\begin{array}{l}\text { - Escuta - eu disse. - Se você faz } \\
\text { mesmo questão, podemos levar horas } \\
\text { nisso. Posso chamar a Marianne } \\
\text { Faithfull ou a Moore, a Charlotte } \\
\text { Brontë ou a Rampling. Muito cultural } \\
\text { e tudo. MAS acontece que estou } \\
\text { trabalhando, gatinha. - O gatinha não } \\
\text { fazia parte de meu glossário, mas } \\
\text { achei que ajudaria. }\end{array}$ & $\begin{array}{l}\text { - Ecoutez, dis-je. Si c'est ce que vous } \\
\text { voulez on peut passer des heures à ce } \\
\text { petit jeu. Je peux demander Marianne } \\
\text { Faithfull ou Moore, Charlotte Brontë } \\
\text { ou Rampling. Ça fait très culturel et } \\
\text { tout et tout. SAUF que je fais mon } \\
\text { travail,ma chatte. - Le chatte ne } \\
\text { faisait pas partie de mon glossaire, } \\
\text { mais je pensai que ça aiderait. }\end{array}$ \\
\hline
\end{tabular}

TradTerm, 16, 2010, p. 313-341 


\begin{tabular}{|c|c|c|c|}
\hline Que & Transposição & $\begin{array}{l}\text { E podia ser, claro, que tanto a mulher } \\
\text { da tarde anterior como a desta não } \\
\text { fosse Dulce Veiga, mas outra } \\
\text { qualquer, que eu fantasiara e } \\
\text { enfeitara; podia ser ainda que não } \\
\text { fosse ninguém mais além de uma } \\
\text { imagem da minha mente; podia ser } \\
\text { também que fosse realmente ela, } \\
\text { MAS tivesse seguido em frente, por } \\
\text { outras ruas, e eu a perdera outra vez. } \\
\text { Mas podia ser, finalmente, que Pepito } \\
\text { e Márcia e Castilhos estivessem } \\
\text { mentindo. }\end{array}$ & $\begin{array}{l}\text { Il était possible, bien sûr, que ni la } \\
\text { femme de la veille ni celle } \\
\text { d'aujourd'hui ne soient Dulce Veiga, } \\
\text { mais une autre femme quelconque, } \\
\text { que j'avais imaginée ou transformée } \\
\text { possible que ce ne soit rien d'autre } \\
\text { qu'une projection de mon esprit } \\
\text { possible aussi que ce soit vraiment } \\
\text { elle, QU'elle } \\
\text { ait poursuivi son chemin dans une } \\
\text { autre direction et que je l'aie perdue à } \\
\text { nouveau. Mais possible aussi, } \\
\text { finalement, que Pepito et et Castilhos } \\
\text { aient menti. }\end{array}$ \\
\hline Même & Transposição & $\begin{array}{l}\text { - Você não me contou que tinha isso, } \\
\text { bofe. Ela é mulher, MAS é uma } \\
\text { deusa. Posso ouvir? }\end{array}$ & $\begin{array}{l}\text { - Tu m'a pas dit que tu l'avais, mec. } \\
\text { Ça c'est une femme, une déesse } \\
\text { MEME. Tu peux l'écouter? }\end{array}$ \\
\hline Malgré & Transposição & $\begin{array}{l}\text { E de repente, como nunca mais } \\
\text { conseguira ver, desde criança, } \\
\text { embora me esforçasse, MAS tinha } \\
\text { perdido aqueles olhos, } \\
\text { inesperadamente consegui enxergar } \\
\text { outra vez São Jorge de lança em } \\
\text { punho, matando o dragão na } \\
\text { superfície da lua. }\end{array}$ & $\begin{array}{l}\text { Et soudain, comme jamias j’avais } \\
\text { réussi à le voir depuis mon enfance, } \\
\text { MALGRE mes efforts car j'avais } \\
\text { perdu ces yeux là, soudain je parvins } \\
\text { de nouveau à distinguer saint } \\
\text { Georges, la lance à la main, tuant le } \\
\text { dragon à la surface de la lune. }\end{array}$ \\
\hline Au fait & Transposição & $\begin{array}{l}\text { - Eu nasci aqui. Sou a dona da } \\
\text { pensão. MAS quem é mesmo que o } \\
\text { senhor está procurando? }\end{array}$ & $\begin{array}{l}\text { - Je suis née ici. C'est moi la } \\
\text { propriétaire de la pension. AU FAIT, } \\
\text { c'est qui que vous cherchez? }\end{array}$ \\
\hline Lorsque & $\begin{array}{l}\text { Transposição } \\
+ \text { Modulação }\end{array}$ & $\begin{array}{l}\text { Não havia ninguém à vista. Tive } \\
\text { vontade de entrar por aquele } \\
\text { corredor, MAS lembrei de Patrícia. }\end{array}$ & $\begin{array}{l}\text { Personne en vu. J'allais entrer dans le } \\
\text { couloir LORSQUE je me souvins de } \\
\text { Patricia. }\end{array}$ \\
\hline Et aussi & $\begin{array}{l}\text { Transposição } \\
+ \text { Modulação }\end{array}$ & $\begin{array}{l}\text { Por alguma razão maluca, ou } \\
\text { absoluta falta de razão, eu não apenas } \\
\text { sentia que tinha que fazer aquilo, } \\
\text { MAS confiava nela. }\end{array}$ & $\begin{array}{l}\text { Pour quelque folle raison, ou } \\
\text { absolument sans raison, je sentais } \\
\text { que je devais le faire, ET AUSSI que } \\
\text { j'avais confiance en elle. }\end{array}$ \\
\hline Quand & $\begin{array}{l}\text { Transposição } \\
+ \text { Modulação }\end{array}$ & $\begin{array}{l}\text { Não tinha nada na cabeça, mas } \\
\text { precisava fingir alguma ocupação } \\
\text { para que Teresinha me deixasse em } \\
\text { paz. } \\
\text { - Você não tem nenhuma nota para } \\
\text { mim? } \\
\text { Eu ia dizer que não, MAS lembrei: } \\
\text { - Você já ouviu falar em Dulce } \\
\text { Veiga? }\end{array}$ & $\begin{array}{l}\text { Je n'avais rien en tête mais il me } \\
\text { fallait feindre une occupation pour } \\
\text { que Teresinha me laissât en paix. } \\
\text { - Vous n'avez pas de potins pour moi } \\
? \\
\text { J'allais lui répondre que non } \\
\text { QUAND je me souvins : } \\
\text { - Vous avez déjà entendu parler de } \\
\text { Dulce Veiga? }\end{array}$ \\
\hline
\end{tabular}

TradTerm, 16, 2010, p. 313-341 
Quadro 3: As traduções de MAS para o inglês.

\begin{tabular}{|c|c|c|c|}
\hline $\begin{array}{c}\text { Corres- } \\
\text { pondente }\end{array}$ & Modalidade & Original em português & Tradução em inglês \\
\hline And & Transposição & $\begin{array}{l}\text { Fiquei tentando descobrir se o cara } \\
\text { de peitos nus, eu precisava de óculos, } \\
\text { seria Arnold Schwarzenneger ou } \\
\text { Sam Shepard, MAS estava achando } \\
\text { que Shepard seria intelectual demais } \\
\text { para o gosto de Jacyr, quando } \\
\text { Jandira disse: } \\
\text {-Axeturá. }\end{array}$ & $\begin{array}{l}\text { I tried to decide whether the bare- } \\
\text { chested Guy - I needed glasses - } \\
\text { was Arnold Schwarzenneger or } \\
\text { Sam Shepard, AND I was thinking } \\
\text { that Shepard would be too } \\
\text { intellectual for Jacyr's taste, when } \\
\text { Jandira said: } \\
\text { "Axeturá." }\end{array}$ \\
\hline And & $\begin{array}{l}\text { Transposição } \\
+ \text { Modulação }\end{array}$ & $\begin{array}{l}\text { Mesmo que a gota se dividisse antes } \\
\text { de entrar no labirinto, era possível } \\
\text { fazer uma parte dela esperar, lá } \\
\text { dentro, por suas partes perdidas, que } \\
\text { chegavam aos poucos, e se } \\
\text { integravam nela. Então primeiro uni- } \\
\text { las numa só, depois fazê-la } \\
\text { escorregar, única, com toda a } \\
\text { suavidade, MAS precisa, por entre as } \\
\text { paredes do labirinto, até o exato } \\
\text { centro geométrico. }\end{array}$ & $\begin{array}{l}\text { At that point join them into one, } \\
\text { then make the single drop slide, } \\
\text { with the utmost gentleness AND } \\
\text { precision, between the walls of the } \\
\text { maze, toward the exact geometric } \\
\text { center. }\end{array}$ \\
\hline \multirow{2}{*}{ Then } & \multirow{2}{*}{$\begin{array}{l}\text { Transposição } \\
+ \text { Modulação }\end{array}$} & $\begin{array}{l}\text { Não havia ninguém à vista. Tive } \\
\text { vontade de entrar por aquele } \\
\text { corredor, MAS lembrei de Patrícia. }\end{array}$ & $\begin{array}{l}\text { There was nobody in sight. I } \\
\text { wanted to go down that hallway, } \\
\text { THEN I remembered Patrícia. }\end{array}$ \\
\hline & & $\begin{array}{l}\text { MAS de repente, quem sabe, a } \\
\text { senhora conheceu também uma } \\
\text { amiga dele. }\end{array}$ & $\begin{array}{l}\text { "Perhaps THEN you also knew a } \\
\text { friend of his." }\end{array}$ \\
\hline \multirow[b]{2}{*}{ Although } & \multirow[b]{2}{*}{$\begin{array}{l}\text { Palavra por } \\
\text { palavra }\end{array}$} & $\begin{array}{l}\text { "Você começa hoje, cara" - dissera } \\
\text { Castilhos no telefone. Com aquela } \\
\text { voz no fundo da qual, para manter o } \\
\text { velho hábito subliterário, eu poderia } \\
\text { localizar algo que chamaria de } \\
\text { áspera-ternura-cúmplice, MAS na } \\
\text { verdade não passava de excesso de } \\
\text { nicotina e saco cheio: "E vê se não } \\
\text { me faz cagada logo no primeiro dia, } \\
\text { oquei? Garanti prós homens que } \\
\text { você é da pesada". }\end{array}$ & $\begin{array}{l}\text { "You start today, pal," Castilhos } \\
\text { had said on the phone. In that voice } \\
\text { at the bottom of which, to feed the } \\
\text { old subliterary habit, I could have } \\
\text { detected something I'd call gruff- } \\
\text { complicitous-fondness, } \\
\text { ALTHOUGH it was actually } \\
\text { nothing but an excess of nicotine } \\
\text { and busted balls. "And see if you } \\
\text { can keep from fucking up on the } \\
\text { very first day, okay? I swore to the } \\
\text { guys you were a hotshot." }\end{array}$ \\
\hline & & $\begin{array}{l}\text { A primeira vez que vi Dulce Veiga, e } \\
\text { foram apenas duas, ela estava } \\
\text { sentada numa poltrona de veludo } \\
\text { verde. Uma bergère, MAS naquele } \\
\text { tempo eu nem sábia que se chamava } \\
\text { assim. Sabia tão pouco de tudo que, } \\
\text { na época, quando tentei descrevê-la } \\
\text { depois na mente e no papel, disse } \\
\text { que era uma dessas poltronas } \\
\text { clássicas, de espaldar alto e assim } \\
\text { como duas abas salientes na altura da } \\
\text { cabeça de quem senta. }\end{array}$ & $\begin{array}{l}\text { The first time I saw Dulce Veiga, } \\
\text { and there were only two times, she } \\
\text { was sitting in a Green velvet } \\
\text { armchair. A bergère, ALTHOUGH } \\
\text { in those days I didn't even know } \\
\text { that was what they were called. I } \\
\text { knew so little of anything in those } \\
\text { days that, later, when I tried to } \\
\text { describe it in my mind and on } \\
\text { paper, I said it was one of those } \\
\text { classic armchairs, with a high back } \\
\text { and something like two wings } \\
\text { jutting out at the height of the head } \\
\text { of the person sitting. }\end{array}$ \\
\hline
\end{tabular}

TradTerm, 16, 2010, p. 313-341 


\begin{tabular}{|c|c|c|c|}
\hline Though & $\begin{array}{c}\text { Palavra por } \\
\text { palavra }\end{array}$ & $\begin{array}{l}\text { Antes que eu talvez recusasse, MAS } \\
\text { não sei se seria capaz, ele meteu a } \\
\text { mão no bolso, arrancou uma carteira } \\
\text { de couro legítimo, com outra águia } \\
\text { lavrada, abriu-a, tirou um monte de } \\
\text { notas. Sem contar, enfiou-as no } \\
\text { bolso da minha camisa. }\end{array}$ & $\begin{array}{l}\text { Before I could refuse, THOUGH I } \\
\text { doubt if I could have, He put his } \\
\text { hand in his pocket, pulled out a } \\
\text { genuine leather wallet with another } \\
\text { eagle engraved on it, opened it and } \\
\text { took out a wad of money. }\end{array}$ \\
\hline $\begin{array}{l}\text { What } \\
\text { about }\end{array}$ & Modulação & $\begin{array}{l}\text { MAS Saul, eu perguntara, quem é } \\
\text { Saul. E Alberto, como Márcia, não } \\
\text { lembrava de ninguém com esse } \\
\text { nome. }\end{array}$ & $\begin{array}{l}\text { WHAT ABOUT Saul, I had asked, } \\
\text { who's Saul. But Alberto, like } \\
\text { Márcia, didn't remember anyone by } \\
\text { that name. }\end{array}$ \\
\hline So & $\begin{array}{l}\text { Transposição } \\
+ \text { Modulação }\end{array}$ & $\begin{array}{l}\text { A sala também parecia uma sala do } \\
\text { interior, modesta e limpa, um sofá de } \\
\text { estampado meio puído, poltronas } \\
\text { combinando, guardanapos de crochê } \\
\text { no espaldar, nos braços. MAS onde } \\
\text { estará afinal o rock and roll, pensei, } \\
\text { olhando a parede com reproduções } \\
\text { de gravuras inglesas do começo do } \\
\text { século. }\end{array}$ & $\begin{array}{l}\text { The living room also looked like a } \\
\text { living room from the interior, } \\
\text { modest and clean, a rather worn } \\
\text { print sofa, matching armchairs, } \\
\text { crocheted doilies on the back and } \\
\text { arms. SO where's the rock ' } n \text { ' roll, } \\
\text { I thought, looking at the wall with } \\
\text { reproductions of English prints } \\
\text { from the beginning of the century. }\end{array}$ \\
\hline When & $\begin{array}{l}\text { Transposição } \\
+ \text { Modulação }\end{array}$ & $\begin{array}{l}\text { Ia desistir sem deixar recado, MAS } \\
\text { alguém desligou a secretária e uma } \\
\text { voz conhecida, irritada, sonolenta, } \\
\text { resmungou um alô. }\end{array}$ & $\begin{array}{l}\text { I was going to hang up without } \\
\text { leaving a message WHEN someone } \\
\text { turned the answering machine off } \\
\text { and a familiar, irritable, sleepy } \\
\text { voice mumbled a hello. }\end{array}$ \\
\hline
\end{tabular}

TradTerm, 16, 2010, p. 313-341 